\title{
Association of Promyelocytic Leukemia Protein with Expression of IL- 6 and Resistance to Treatment in Multiple Myeloma
}

\author{
Daisuke Ohgiya $^{a}$ Hiromichi Matsushita ${ }^{b}$ Makoto Onizuka ${ }^{a}$ Naoya Nakamurac \\ Jun Amaki ${ }^{a}$ Yasuyuki Aoyama ${ }^{a}$ Hidetsugu Kawai ${ }^{a}$ Yoshiaki Ogawa ${ }^{a}$ \\ Hiroshi Kawada ${ }^{a}$ Kiyoshi Ando ${ }^{a}$ \\ ${ }^{\mathrm{a} D i v i s i o n}$ of Hematology/Oncology, Department of Internal Medicine, and Departments of ${ }^{\mathrm{b}}$ Laboratory Medicine

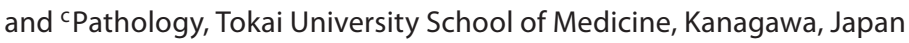

\section{Key Words}

Chemokines • Cytokines • Interleukin-6 - Multiple myeloma • Promyelocytic leukemia

\begin{abstract}
Background/Aims: Promyelocytic leukemia protein (PML) was originally identified as a tumor suppressor but has been recently shown to have the ability to control stem cell function in multiple tissues including malignancies. This study aimed to evaluate the biological and clinical significance of PML in multiple myeloma (MM). Methods: We knocked down PML in myeloma cells with a lentiviral vector expressing microRNA to target PML, which were used for in vitro analyses. We also evaluated the association between PML expression in the bone marrow and patients' clinical parameters. $R \boldsymbol{e}$ sults: The expression of IL- 6 was decreased in myeloma cells with knocked-down PML expression. Immunohistochemical study showed that the PML expression level varied widely in the bone marrow of $48 \mathrm{MM}$ patients, and that IL- 6 expression correlated with PML expression in these patients. In addition, MM with high PML expression at diagnosis showed a poor prognosis regarding the 2-year survival, and PML and IL-6 positivity increased with the progression of disease in 13
\end{abstract}

sequentially analyzed cases. Conclusions: These results suggest that PML expression was positively associated with IL-6 expression in patients and was also related to tumor development and resistance to treatment in $\mathrm{MM}$.

Copyright $\odot 2012$ S. Karger AG, Basel

\section{Introduction}

Multiple myeloma (MM) is a malignant neoplasm of plasma cells that is incurable because myeloma cells are difficult to eradicate by current therapeutic approaches. MM occurs most frequently in the elderly, with a median age at diagnosis of 66 years [1]. MM is a heterogeneous disease entity, and patients with MM show heterogeneous prognoses that range from a relatively indolent course with a lengthy survival period to a more aggressive course with a poor prognosis.

Many studies have revealed the bone marrow microenvironment to be an important contributor to MM tumorigenesis [2, 3]. Myeloma cells express a number of different cell adhesion molecules including CD44, VLA-4, VLA-5, CD56, syndecan-1, and MPC-1. These molecules permit attachment to stromal cells and to the extracellu-

\section{KARGER}

Fax +4161306 1234

E-Mail karger@karger.ch

www.karger.com
(C) 2012 S. Karger AG, Basel

$0001-5792 / 12 / 1284-0213 \$ 38.00 / 0$

Accessible online at:

www.karger.com/aha
Kiyoshi Ando, MD, $\mathrm{PhD}$

Division of Hematology/Oncology, Department of Internal Medicine

Tokai University School of Medicine

143 Shimokasuya, Isehara, Kanagawa 259-1193 (Japan)

Tel. +81 46393 1121, E-Mail andok@ keyaki.cc.u-tokai.ac.jp 
lar matrix. Bone marrow stromal cells, or even myeloma cells themselves, secrete cytokines including IL-6, TNF, TGF- $\beta$, IGF-1, and VEGF, which act via their receptors on the surface of myeloma cells. These interactions enhance tumor growth, survival, migration, and drug resistance. IL-6 is one of the most important cytokines because it activates multiple cell survival and proliferation signaling pathways in myeloma cells. These include the Janus kinase/signal transducer and activator of transcription 3 (JAK/STAT-3) pathway, the mitogen-activated protein kinase/extracellular signal-related kinase (MEK/ ERK) pathway, and the phosphoinositide 3-kinase (PI3$\mathrm{K}) /$ Akt pathway [4]. IL- 6 functions in either an autocrine and/or a paracrine manner [5-8].

Promyelocytic leukemia (PML) protein was originally identified as a tumor suppressor that has a variety of cellular functions in a nuclear macromolecular structure called the PML nuclear body (PML-NB). The PML-NB interacts with a large number of intranuclear proteins, including $\mathrm{p} 53, \mathrm{Rb}, \mathrm{Daxx}$, and CBP, to regulate and modify a variety of cellular functions [9-11]. The loss of PML protein expression is associated with tumor progression in prostate cancer, breast cancer, and central nervous system tumors [12]. Reduced expression of PML is associated with poor survival in patients with gastric carcinomas [13].

However, a recent study has shown that the PML-NB is also responsible for resistance to chemotherapy in tumor-initiating cells of chronic myeloid leukemia (CML) and their maintenance by regulating the cell cycle, thus suggesting that PML also plays an important role in the self-renewal and survival of cancer stem cells as well as normal stem cells [14]. Few studies have so far demonstrated either the role or the function of PML in myeloma cells.

The purpose of this study was to investigate the involvement of PML in the pathogenesis of MM.

\section{Materials and Methods}

\section{Cells and Reagents}

Human myeloma cell lines, RPMI8226 and IM9, were obtained from the Japanese Collection of Research Bioresources cell bank (Osaka, Japan), and U266 cells were kindly provided by Dr. Shinsuke Iida (Nagoya City University, Aichi, Japan). All lines were maintained in RPMI 1640 medium supplemented with $10 \%$ heat-inactivated fetal bovine serum, $100 \mathrm{U} / \mathrm{ml}$ penicillin, and 100 $\mu \mathrm{g} / \mathrm{ml}$ streptomycin in a humidified atmosphere $\left(37^{\circ} \mathrm{C}, 5 \% \mathrm{CO}_{2}\right)$. The cytotoxic agents used in this study were melphalan, dexamethasone (Wako, Osaka, Japan) and doxorubicin (Kyowa Hakko Kirin, Tokyo, Japan). The retrovirus pMY-IG was kindly pro- vided by Dr. Toshio Kitamura (Institute of Medical Science, University of Tokyo, Tokyo, Japan), and it was used for overexpression of PML isoform 6 obtained by PCR.

Knockdown of PML in Myeloma Cells

Artificial interfering microRNAs (miR RNAi) were designed and generated by Invitrogen (Carlsbad, Calif., USA) to target all variants of PML (miR-PML; top 5'-TGCTGTCTTGGATACAGCTGCATCTTGTTTTGGCCACTGACTGACAAGATGCATGTATCCAAGA-3'; bottom 5'-CCTGTCTTGGATACATGCATCT-TGTCAGTCAGTGGCCAAAACAAGATGCAGCTGTATCCA-AGAC-3') and LacZ (miR-LacZ; top 5'-TGCTGAAATCGCTGATTTGTGTAGTCGTTTTGGCCACTGACTGACGACTACACATCAGCGATTT-3'; bottom 5'-CCTGAAATCGCTGATGTGTAGTCGTCAGTCAGTGGCCAAAACGACTACACAAATCAGCGATTTC-3'). Each miR RNAi was cloned into the BLOCK-iT Pol II miR RNAi expression vector (Invitrogen), according to the manufacturer's instructions, and then sequenced. Production of the lentivirus vectors and their infection into myeloma cells were performed using a BLOCK-iT HiPerform Lentiviral Pol II miR RNAi Expression System with EmGFP (Invitrogen), according to the manufacturer's instructions. GFP-positive cells were sorted using BD FACS Vantage (BD, Franklin Lakes, N.J., USA) to obtain the fraction of transduced cells.

\section{Immunofluorescent Analysis of PML in Myeloma Cells}

The cells were permeabilized five times in $0.1 \%$ Triton $\mathrm{X}$ for 5 min each, and they then were sequentially fixed in $4 \%$ formaldehyde for $15 \mathrm{~min}$ at room temperature (RT) and washed five times in PBS for 5 min each. After incubation in 5\% normal goat serum dissolved in PBS for $1 \mathrm{~h}$ at RT, the cells were incubated with a rabbit polyclonal antiserum against PML protein (1:200; Abcam, Cambridge, Mass., USA) overnight at $4^{\circ} \mathrm{C}$. The cells were then washed five times in PBS for 5 min each and incubated with anti-rabbit Alexa 594 (1:200; Invitrogen) for $30 \mathrm{~min}$ at RT and for $1 \mathrm{~h}$ at $4^{\circ} \mathrm{C}$. The nuclei were counterstained with DAPI.

\section{Western Blot Analysis of PML in Myeloma Cells}

The cells were harvested and washed, and then the pellets were suspended with $0.1 \mathrm{ml}$ of ice-cold TNE buffer and incubated on ice for $10 \mathrm{~min}$. The lysates were then centrifuged, and the supernatants were boiled in SDS sample buffer. The proteins were separated by SDS-polyacrylamide gel electrophoresis and transferred to nitrocellulose membranes. The proteins were detected by the ECL Plus Western blotting analysis system (Amersham Pharmacia, Piscataway, N.J., USA) using anti-PML (Bethyl, Montgomery, Tex., USA) and anti- $\beta$-actin antibodies (Sigma-Aldrich, St. Louis, Mo., USA).

\section{Cell Growth Assay and Cell Cycle Analysis}

Cellular proliferation was evaluated using a WST-8 viability assay kit (Invitrogen), according to the manufacturer's protocol. Briefly, $1 \times 10^{4}$ cells were incubated for $48 \mathrm{~h}$ in $60 \mu \mathrm{l}$ of medium in a 96-well plate. The cells were incubated with $10 \mu \mathrm{l}$ of WST-8 solution for $2 \mathrm{~h}$. Absorbance was measured at $440 \mathrm{~nm}$ using a Spectra Max 250 microplate ELISA reader (Molecular Devices, Sunnyvale, Calif., USA) to detect metabolically intact cells. The cell cycle in GFP-expressing cells was analyzed using Hoechst 33342 dye and a BD LSRFortessa (BD). 
Analysis of RNA Expression

Total RNA was extracted from the cells with Isogen (Nippon Gene, Tokyo, Japan) according to the manufacturer's instructions. First strand cDNA synthesis was performed using a SuperScript VILO cDNA Synthesis Kit (Invitrogen).

Real-time RT-PCR was performed using an ABI PRISM 7300 DNA analyzer (Applied Biosystems, Foster City, Calif., USA). The mixtures of cDNA, TaqMan Gene Expression Master Mix, and Taqman probes for PML, IL-6, and housekeeping gene 18s rRNA (Applied Biosystems) were denatured at $95^{\circ} \mathrm{C}$ for $10 \mathrm{~min}$, followed by 40 cycles at $95^{\circ} \mathrm{C}$ for $15 \mathrm{~s}$ and at $60^{\circ} \mathrm{C}$ for $1 \mathrm{~min}$.

The gene expression profile was evaluated using a SurePrint G3 Human GE 8x60K Microarray (Agilent Technologies, Santa Clara, Calif., USA). Cy3-labeled cRNA samples from RPMI8226 cells with miR-PML or miR-LacZ (control) were hybridized using the Gene Expression Hybridization Kit. The data analysis was performed using the GeneSpringGX software package version 11.0.4 (Agilent Technologies). Significant changes in RNA expression in the microarray analysis were defined as upregulation or downregulation by more than 1.5 -fold. The $\mathrm{p}$ values in the gene ontology analysis were identified by Fisher's exact test.

\section{Patients}

MM patients whose bone marrow clot sections were available before any therapy at the Tokai University Hospital (Kanagawa, Japan) from January 1998 to December 2009 were analyzed according to the appropriate procedure approved by the Institutional Review Board of our institution and after obtaining written informed consent from all participants. Clinical staging was performed according to the International Staging System for Multiple Myeloma (ISS) [15].

Immunohistochemical Staining of Bone Marrow Specimens

Immunohistochemistry was performed using paraffin-embedded sections of aspirated bone marrow clots. Expression of PML was detected using the double immunoperoxidase staining technique according to the company's protocols (Bond Polymer AP Red Detection and Bond Polymer Refine Detection; Vision Biosystems, Newcastle upon Tyne, UK) with anti-PML (Santa Cruz, Calif., USA) and anti-CD138 antibodies (DakoCytomation, Glostrup, Denmark). Expression of Ki67 was detected using antiKi67 antibody (Vision Biosystems) with the same protocol as anti-CD138 in order to evaluate myeloma cell proliferation. Expression of cytoplasmic IL- 6 was detected using anti-IL-6 antibody (Vision Biosystems).

\section{Statistical Analysis}

The Kaplan-Meier method was used to estimate the patients' survival. Log-rank p values were used for comparison of survival outcomes among subgroups of patients. The PML-positive ratios between 'at diagnosis' and 'after treatment' were compared using paired $t$ tests. The results are reported as means \pm SD for experiments performed with three replicates samples and were compared using Student's t test. $\mathrm{p}<0.05$ was considered statistically significant. These statistical analyses were conducted using the GraphPad Prism software package (GraphPad Software, La Jolla, Calif., USA) and SPSS 15.0 (SPSS, Chicago, Ill., USA).

\section{Results}

Downregulation of PML in Myeloma Cells Does Not Affect Either Proliferation or Chemosensitivity in vitro

PML-expressing retroviral vector was introduced into the myeloma cell lines to investigate the biological function of PML in myeloma cells, but the living cells with PML overexpression were not observed to be glowing. The PML expression was then knocked down with miR RNAi directly interfering PML (miR-PML) in three myeloma cell lines: RPMI8226, U266, and IM9 cells. MiRPML knocked-down PML mRNA to $0.23,0.50$, and 0.36 times in RPMI8226, U266, and IM9 cells, respectively (fig. 1a), while also reducing PML-NB in RPMI8226 cells (fig. 1b, c). Furthermore, the PML protein levels in RPMI8226 and IM9 cells transduced with miR-PML construct, especially the largest and abundant PML isoforms corresponding to isoforms I and II, were reduced in comparison to the levels in the cells transduced with miRLacZ construct (control) (fig. 1d). The cellular proliferation and cell cycle status were evaluated using WST-8 and a two-color flow cytometric analysis with GFP expression and Hoechst 33342, respectively. Neither of these parameters was affected (data not shown). The downregulation of PML did not change the sensitivity to cytotoxic agents such as melphalan, dexamethasone, and doxorubicin as determined by evaluation of the $\log \mathrm{IC}_{50}$ (data not shown). These findings suggest that the PML expression in myeloma cells does not simply affect cellular proliferation and the sensitivity to cytotoxic agents in a cell-autonomous manner.

\section{Expression Analysis of Transcripts in PML}

Knocked-Down Myeloma Cells

A microarray analysis of RPMI8226 cells transduced with either miR-PML or miR-LacZ construct was used to investigate whether PML regulates the gene expression in myeloma cells. The following changes in RNA expression $>1.5$-fold were detected in RPMI8226 cells transduced with miR-PML construct in comparison to those transduced with miR-LacZ construct. A total of 942 probes were upregulated including CD44 (1.82-fold), CCL-5 (2.05-fold), CCR-4 (6.25-fold), FGFR-1 (1.52-fold), and IL-17C (1.74-fold), and 1,042 probes were downregulated including PML (3.64-fold), IL-6 (2.79-fold), IL-8 (1.90fold), CXCL-2 (1.62-fold), CXCL-3 (1.78-fold), CXCL-6 (1.82-fold), CXCL-9 (2.35-fold), CXCL-10 (3.24-fold), CXCR-2 (2.14-fold), and CXCR-3 (1.63-fold). VLA-4, VLA-5, CD56, CD138, MPC-1, TNF- $\alpha$, TGF- $\beta$, and VEGF showed no significant fold changes. 


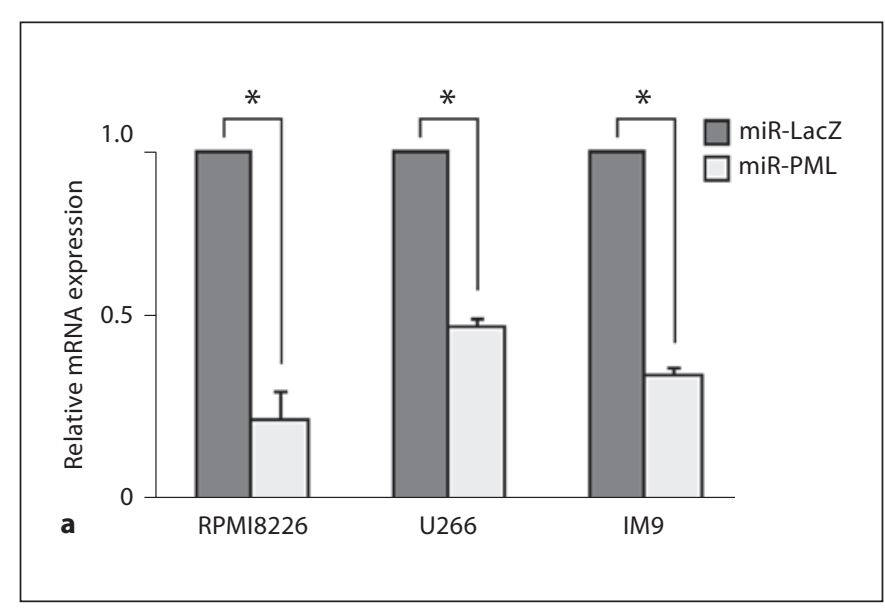

miR-LacZ
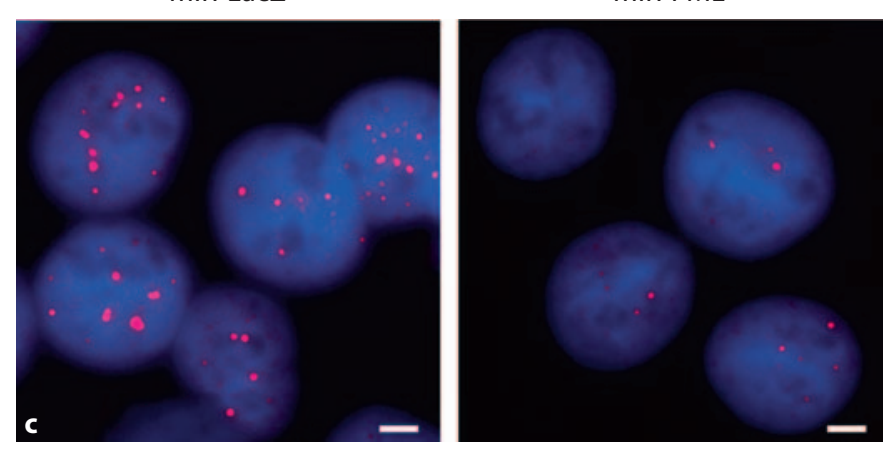

Fig. 1. Knockdown of PML expression in three myeloma cell lines. a Relative mRNA levels of PML in RPMI8226, U266, and IM9 cells transduced with miR-PML construct. The cells transduced with miR-LacZ construct were used as a control. ${ }^{*} \mathrm{p}<0.01$. b Numbers of PML-NBs in the cells transduced with either miRPML or miR-LacZ construct. ${ }^{*} \mathrm{p}<0.01$. c Immunofluorescent analysis of PML-NB (red) in RPMI8226 cells transduced with either miR-PML or miR-LacZ construct. Scale bars $=2 \mu \mathrm{m}$. d Western blot analysis of the PML protein in RPMI8226 and IM9 cells transduced with either miR-PML (PML knockdown; KD) or miRLacZ (control; Ctrl). The expression of $\beta$-actin was used as an internal control. e Relative mRNA levels of IL-6 in RPMI8226, U266, and IM9 cells transduced with either miR-PML or miRLacZ construct. * $\mathrm{p}<0.01$.
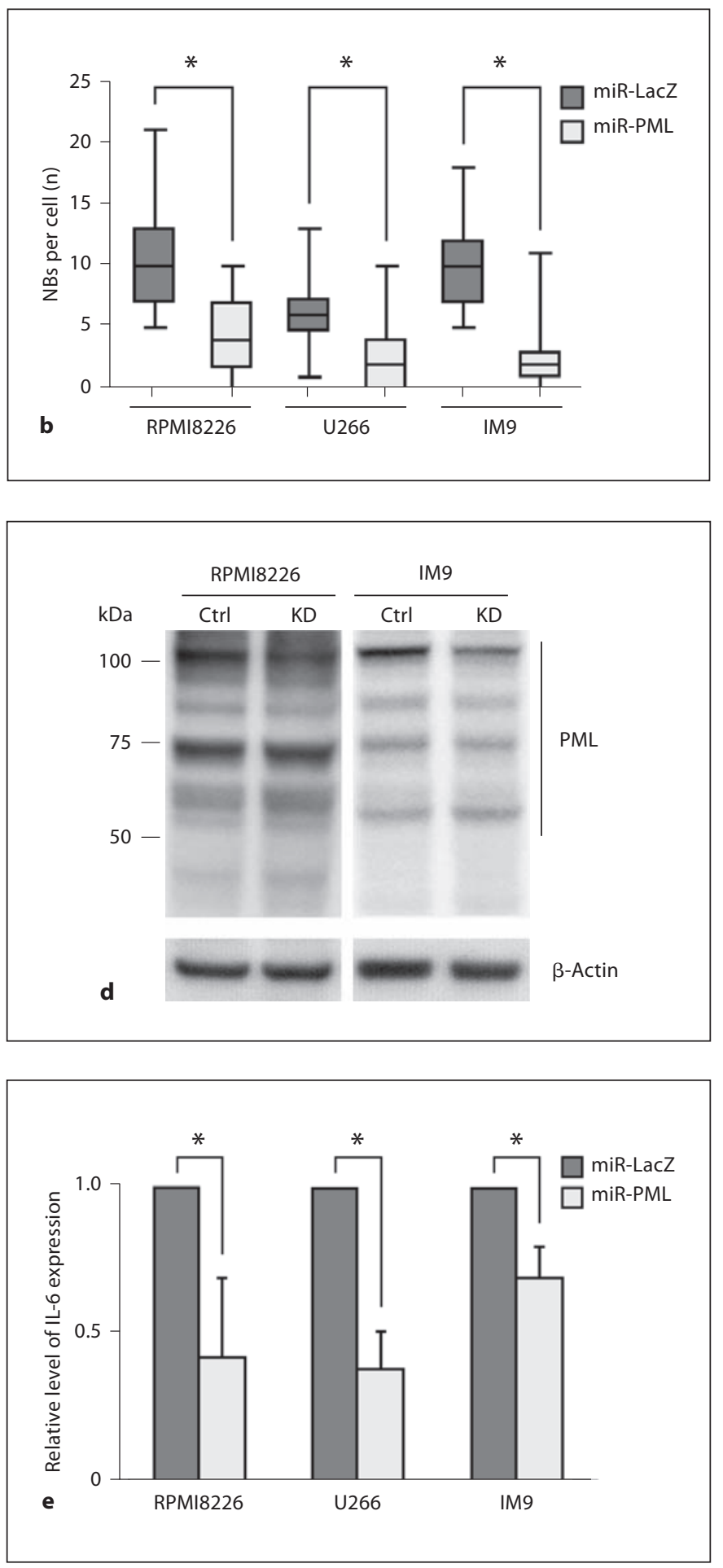
The gene ontology analysis extracted eight categories from the microarray data and IL- 6 was included in six of those eight categories (table 1). Real-time RT-PCR revealed the IL- 6 expression to be downregulated in all three myeloma cell lines transduced with miR-PML construct (fig. 1e).

\section{PML Expression in MM Patients}

Next, the PML expression in 48 patients with MM, who presented before receiving any therapy at Tokai University Hospital, was evaluated using their bone marrow clot sections. All of the patients underwent combination initial chemotherapies containing alkylating agents. There were 17 patients at ISS stage I, 14 at stage II, and 17 at stage III (table 2).

The PML-positive ratio of myeloma cells ranged widely from $0-83.8 \%$ and was evaluated as the percentage of PML+/CD138+ cells in all CD138+ cells from a double stained bone marrow clot section. The patients were divided into three groups based on the PML-positive ratio: negative/low (12 cases, $25 \%$ of all 48 cases), intermediate (24 cases, 50\%), and high (12 cases, $25 \%$ ) (fig. $2 \mathrm{a}, \mathrm{b}$ ). The PML-positive ratios in the negative/low, intermediate, and the high groups were $0-22.1 \%, 22.1-56.6 \%$, and $56.6-$ $83.8 \%$, respectively.

\section{PML Expression Was Positively Associated with IL-6 \\ Expression in MM Patients}

The proliferation of myeloma cells in bone marrow clots in vivo was investigated because PML is believed to regulate cellular proliferation. The Ki67-positive rate in myeloma cells was evaluated in $48 \mathrm{MM}$ cases and ranged from 0 to $53.8 \%$. The levels of PML expression, however, did not correlate with the Ki67-positive ratios (Spearman's correlation coefficient $=-0.13, \mathrm{p}=0.36$ ).

The association between PML and IL- 6 expression was also evaluated using bone marrow cells from the negative/low and high PML groups. Cytoplasmic IL- 6 was detected in 7 out of the 12 cases (58\%) in the high PML group and in 8 out of the 24 cases $(33.3 \%)$ in the intermediate group, whereas none of the 12 cases $(0 \%)$ in the negative/low PML group was positive for IL-6 (fig. 3a, b). Statistical analysis showed that the IL- 6 positivity of the high and intermediate PML group was significantly higher than that of the negative/low PML group ( $\mathrm{p}=0.0046$ and $\mathrm{p}=0.033$, respectively). This suggests that PML expression correlates with IL- 6 expression in clinical samples, as is observed in myeloma cells in vitro.
Table 1. Gene ontology terms extracted by gene expression profiles in the comparison of RPMI8226 cells transduced with either miR-PML or miR-LacZ construct

\begin{tabular}{lll}
\hline $\begin{array}{l}\text { Gene ontology } \\
\text { accession }\end{array}$ & Gene ontology term & p value $^{\mathrm{b}}$ \\
\hline GO:0006952 & defense response $^{\mathrm{a}}$ & 0.0115 \\
GO:0016337 & cell-cell adhesion $^{\text {inflammatory response }} \mathrm{a}^{\mathrm{a}}$ & 0.0302 \\
GO:0006954 & cadmium ion binding $^{\mathrm{a}}$ & 0.0302 \\
GO:0046870 & plasma membrane $^{\mathrm{a}}$ & 0.0302 \\
GO:0005886 & response to wounding $^{\mathrm{a}}$ & 0.0344 \\
GO:0009611 & intrinsic to membrane \\
GO:0031224 & 0.0369 \\
GO:0016021 & integral to membrane & 0.0369 \\
\hline
\end{tabular}

${ }^{\mathrm{a}}$ Gene ontology for IL-6. ${ }^{\mathrm{b}}$ Corrected p value.

Table 2. Clinical characteristics and outcomes of 48 multiple myeloma patients

\begin{tabular}{|c|c|}
\hline Median age, years & $62.5(38-76)$ \\
\hline Male/female ratio & $26 / 22$ \\
\hline \multicolumn{2}{|l|}{ Immunoglobulin isotype, $\mathrm{n}$} \\
\hline $\operatorname{IgG}$ & 24 \\
\hline IgA & 9 \\
\hline IgD & 2 \\
\hline Light chain & 11 \\
\hline \multicolumn{2}{|l|}{ ISS stage, $\mathrm{n}$} \\
\hline I & 17 \\
\hline II & 14 \\
\hline III & 17 \\
\hline Median serum $\beta_{2}$-microglobulin, mg/l & $6.7(0.94-37.7)$ \\
\hline Median serum albumin, g/dl & $3.8(2.3-5.0)$ \\
\hline Median serum creatinine, $\mathrm{mg} / \mathrm{dl}$ & $1.38(0.4-10)$ \\
\hline Median hemoglobin, g/dl & $10.7(6.6-14.0)$ \\
\hline Median platelet count, $\times 10^{9} / 1$ & $190(68-452)$ \\
\hline Median bone marrow plasma cell count, \% & $25.2(10.2-94.2)$ \\
\hline \multicolumn{2}{|l|}{ Initial therapy, $\mathrm{n}$} \\
\hline $\mathrm{VAD}$ & 23 \\
\hline MP & 17 \\
\hline VMP & 2 \\
\hline Other & 6 \\
\hline \multicolumn{2}{|l|}{ Stem cell transplantation, $\mathrm{n}$} \\
\hline Allo BMT & 2 \\
\hline Auto PBSCT & 9 \\
\hline
\end{tabular}

Figures in parentheses are range.

VAD = Vincristine, adriamycin, dexamethasone; $\mathrm{MP}=$ melphalan, prednisolone; VMP = melphalan, prednisolone, bortezomib; BMT = bone marrow transplantation; $\mathrm{PBSCT}=$ peripheral blood stem cell transplantation. 
Fig. 2. $P M L$ expression in bone marrow specimens from 48 newly diagnosed MM patients. Bone marrow clot sections were stained with anti-PML antibody (red in the cell nucleus) and anti-CD138 antibody (brown at the cell membrane). CD138positive myeloma cells with at least three dots of PML were counted as PML-positive cells, and the proportion of them relative to all CD138-positive myeloma cells was defined as the PML-positive ratio. a PML-positive ratios in $48 \mathrm{MM}$ patients. They ranged widely from 0 to $83.8 \%$. The patients were divided into three groups, according to the PML-positive ratio. The 12 negative/low cases, the 12 high cases, and the 24 residual cases were defined to be the negative/low, high, and intermediate groups, respectively. b An example from each group is herein presented. Scale bars $=10 \mu \mathrm{m}$.
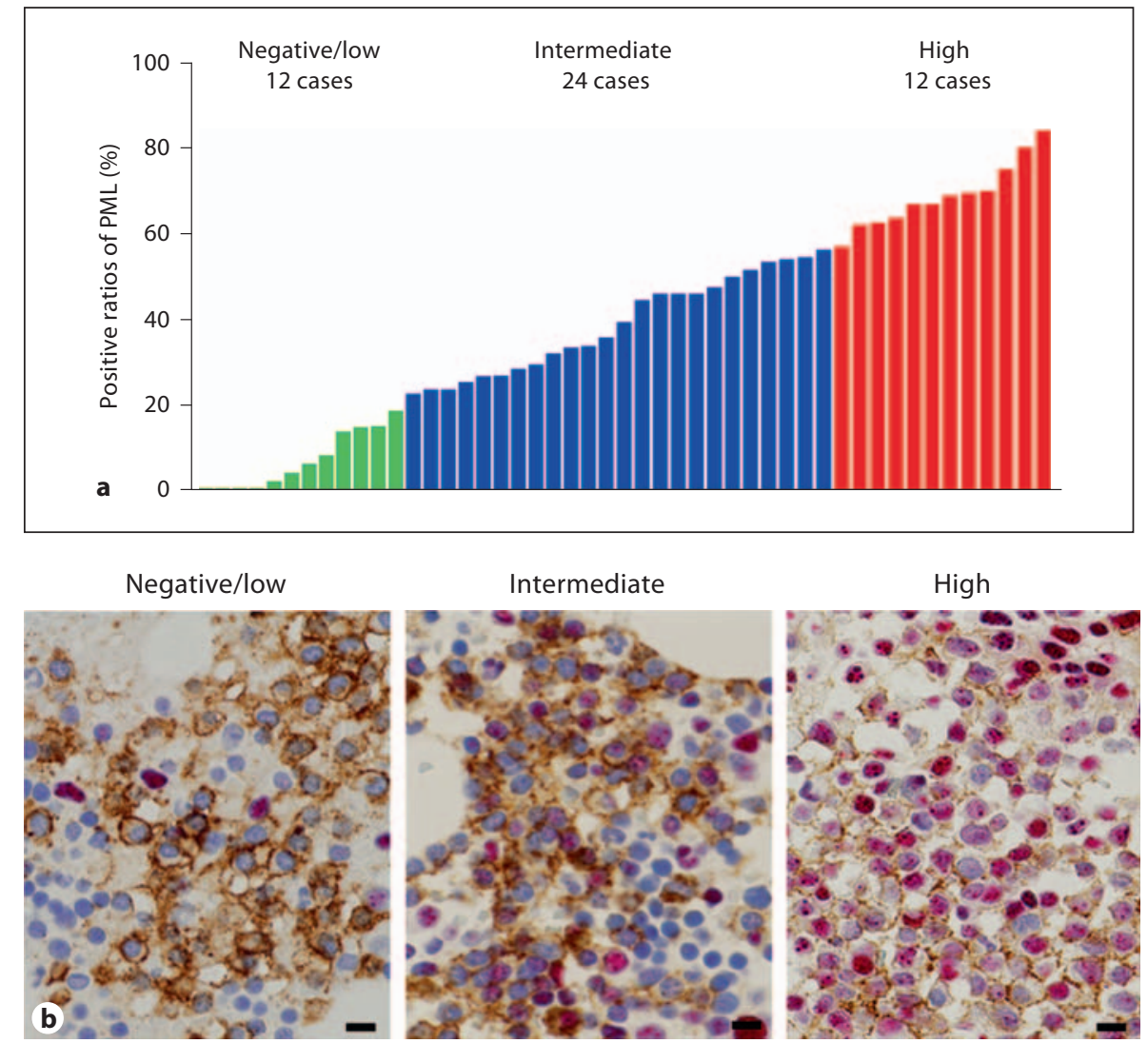

Impact of PML Expression on the Prognosis of MM

Patients

The clinical impact of PML expression in myeloma cells was examined in MM patients and thus revealed a significant difference in the 2-year survival among the three groups (negative/low, 100\%; intermediate, $85.2 \%$, and high, $54.7 \% ; \mathrm{p}=0.015$; fig. 4 ), There was also a significant difference between the 2-year survival of the negative/low and intermediate groups in comparison to the high group ( 89.2 and $54.7 \%, \mathrm{p}=0.0053$ ). No significant correlation was observed between PML expression and ISS stage using a nonparametric method (Spearman's correlation coefficient $0.083, \mathrm{p}=0.57$ ).

However, the negative/low PML group eventually demonstrated no advantage in the overall survival of these 3 groups ( $p>0.05)$. We hypothesized that chemotherapy-resistant myeloma cells were selected during the clinical course with multiple treatments, resulting in the deterioration of the disease status. Therefore, the changes in PML positivity were evaluated in $13 \mathrm{MM}$ patients whose bone marrow samples were available at diagnosis and after treatment. The PML-positive ratios were sig- nificantly higher with disease progression after treatment than at diagnosis ( $\mathrm{p}=0.0042$; fig. $5 \mathrm{a}, \mathrm{b})$. None of the 13 cases showed IL- 6 positive staining at diagnosis (0\%); however, 7 of them expressed IL-6 after treatment (53.8\%). There were three cases belonging to the negative/low PML group. Their PML-positive ratios were progressively increased $(0.3-82.6 \%, 14.1-100 \%$, and $19.0-37.5 \%)$, and two of them died due to disease progression. On the other hand, two patients whose PML-positive ratios decreased after treatment lived more than 5 years without therapy. These findings suggest that the expressions of PML and IL-6 are correlated, and that such expressions correspond to disease progression.

\section{Discussion}

This study examined both the biological and the clinical significance of PML in myeloma cells. The knockdown of PML expression affected neither cellular proliferation nor chemotherapy-resistance in a cell-autonomous manner, but it reduced the expression of IL-6. PML 


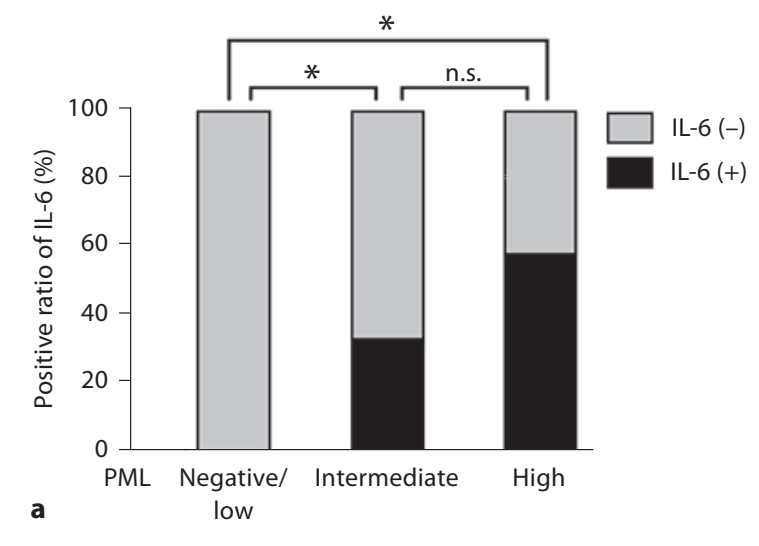

Fig. 3. IL-6 expression in bone marrow specimens from MM patients. a Comparison of IL-6 expression in the PML negative/low, intermediate, and high groups. ${ }^{*} \mathrm{p}<0.05$. n.s. $=$ Not significant. b Representative cases with or without IL- 6 expression. The left panel corresponds to the PML negative/low group and the right panel to PML high group. Bone marrow clot sections were stained with anti-IL-6 antibody (brown in the cell nucleus). Scale bars $=20 \mu \mathrm{m}$.
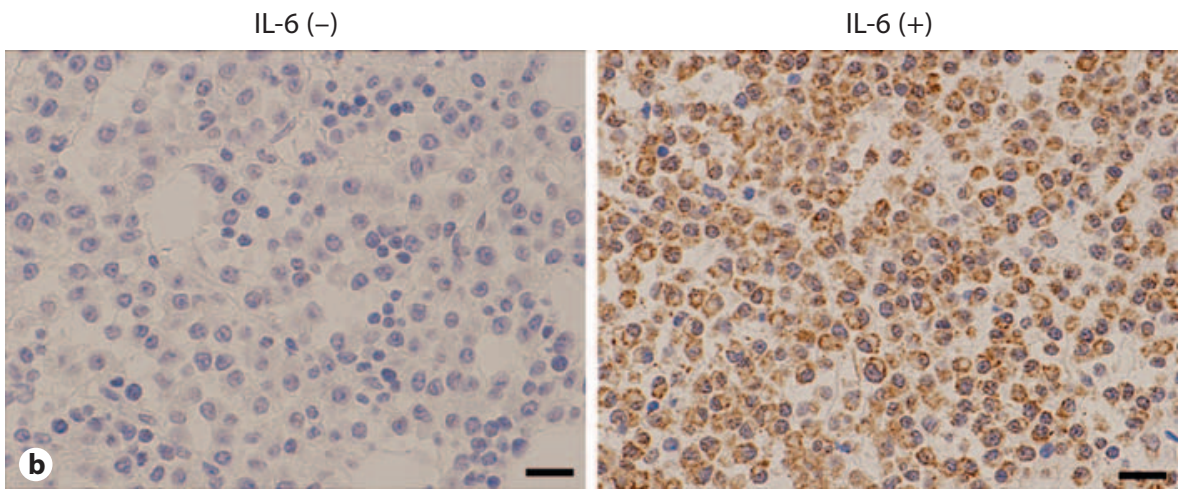

expression was positively associated with IL-6 expression in bone marrow from MM patients. Retrospective observations revealed that a high expression of PML at diagnosis was related to a poor prognosis in the 2-year survival of MM and that the PML expression increased during the clinical course of $\mathrm{MM}$, leading to patient deterioration. Taken together, these findings suggest that PML is important for disease progression and failure to respond to therapy in $\mathrm{MM}$, probably through the upregulation of IL-6.

PML regulates cellular proliferation and apoptosis in normal cells. PML also plays an important role in regulating physiological processes and tissue homoeostasis, including self-renewal, in cancer stem cells [16]. Cancer stem cells including leukemic stem cells (LSCs) are required for the maintenance of malignant diseases [17]. LSCs are normally quiescent and lodged in the bone marrow niche where, like normal hematopoietic stem cells, they are resistant to chemotherapy [18]. A high expression of PML induces resistance to chemotherapy in CMLLSC by regulating their cell cycle and it results in a poor prognosis in in vivo CML models [14]. It is therefore pos-

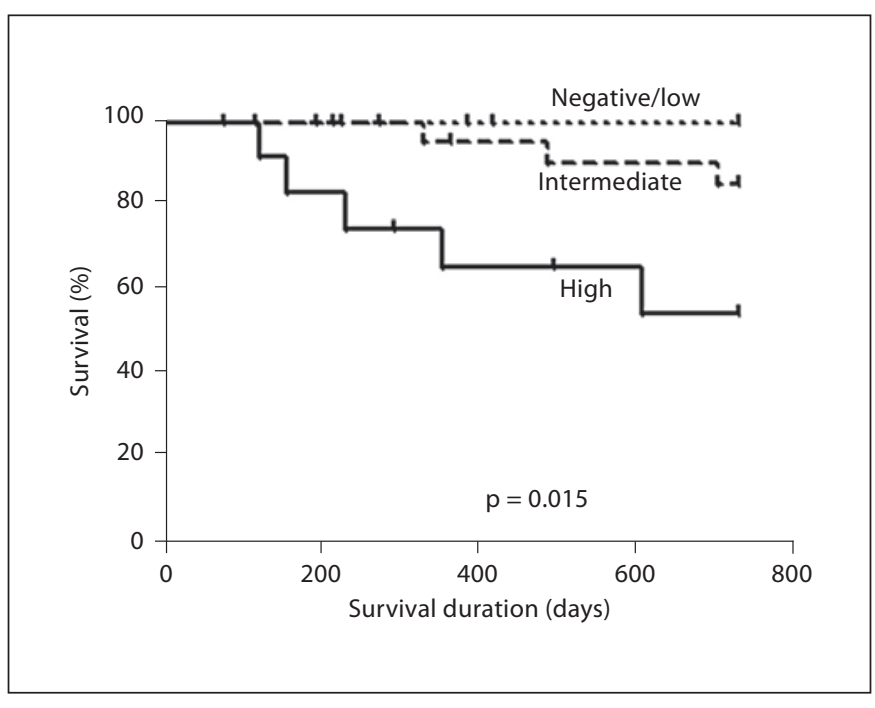

Fig. 4. Two-year survival of $48 \mathrm{MM}$ patients according to PML expression. 


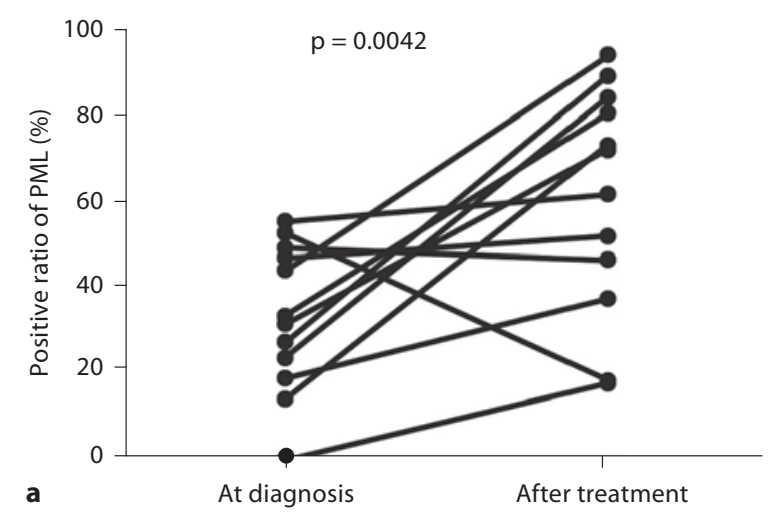

Fig. 5. PML-positive ratios increased after chemotherapy in MM patients. a Comparison of the PML expression between 'at diagnosis' and 'after chemotherapy' in 13 MM patients. b A representative case is shown. The left and right panels are 'at diagnosis' and 'after chemotherapy', respectively. PML is red; CD138 is brown. Scale bars $=20 \mu \mathrm{m}$.
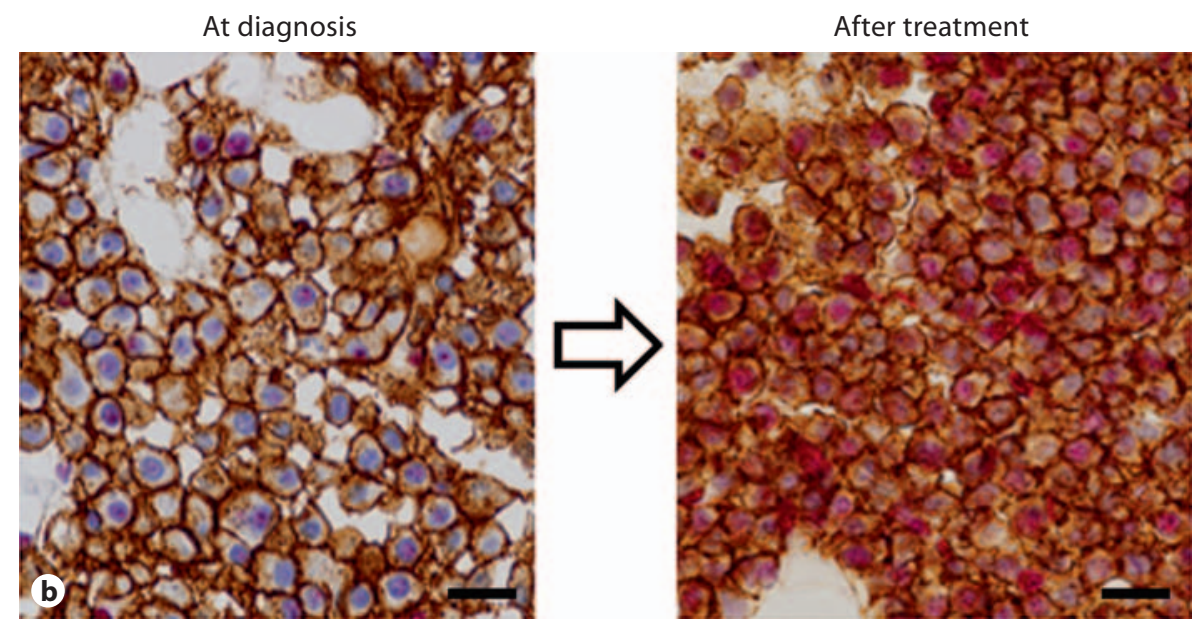

sible that PML causes resistance to chemotherapy in hematopoietic malignancies with a dormant proliferation of LSCs, which thus leads to disease progression and deterioration. The relationship between the high expression of PML and the poor prognosis in MM shown here suggests that PML also contributes to chemotherapy resistance, rather than their less-proliferative nature, in myeloma cells. This possibility was supported by the increased PML positivityassociated with disease progression in the current study in addition to the analysis using the myeloma cell line ARH77 treated with $\gamma$-radiation, melphalan, bortezomib, or INF $\alpha$ [19].

The in vitro studies using myeloma cells with knockeddown PML expression did not show any differences in biological function and chemotherapy resistance between high and low PML expression in myeloma cells. These results suggest that PML does not simply inhibit cellular proliferation in a cell-autonomous manner. $\mathrm{Hu}-$ moral factors and intercellular interaction regulated by
PML may externally contribute to regulating the proliferation and apoptosis of myeloma cells.

The interaction of myeloma cells with bone marrow stromal cells is important for their homing pattern, survival, and proliferation [20]. The current microarray analysis demonstrated that PML is associated with expression levels of various cytokines and chemokines including IL-6, IL-8, CXCL-9, CXCL-10, and the receptors CXCR-2 (the IL-8 receptor), and CXCR-3 (the CXCL-9 and CXCL-10 receptor). Bone marrow stromal cells express IL-8, which stimulates the proliferation of myeloma cells through CXCR-2 on their surface. IL- 8 is also implicated in tumor progression probably via its ability to enhance angiogenesis [21,22], which is also crucial for myeloma development. Moreover, recent evidence indicates that CXCL-10 and CXCR-3 may also be involved in the proliferation and survival of myeloma cells [23]. However, the in vitro study showed that the proliferation of myeloma cells with knocked-down PML expression was not 
affected, in spite of the modulated cytokine/chemokine system. These findings suggest that the survival of myeloma cells is not directly stimulated via autocrine signaling, but it is indirectly supported by the microenvironment. Further analyses in co-culture or an in vivo model are therefore required to characterize the interaction of PML with these cytokine and chemokine systems in myeloma cells.

The mechanism by which PML upregulates IL- 6 is unknown. PML and IL-6 are supposed to conversely affect cellular proliferation. IL-6 induces desumoylation and inactivation of PML [24]. However, exogenous IL-6 was reported to induce PML-NB in response to the recognition of intracellular bacterial lipoprotein, similar to the DNA damage [25]. Both PML and IL-6 possess numerous functions in cellular survival and responses. Therefore, it is possible that PML and IL- 6 collaborate directly or indirectly in specific conditions such as tumorigenesis. In fact, it has recently been demonstrated that IL- 6 production is reduced in PML knockout mice [26]. Further study is therefore required to reveal this mechanism, which could provide us with useful clues to establish a novel therapeutic approach against this refractory disease.

A number of cell modulators are currently utilized for the treatment of MM including proteasome inhibitors, immunomodulatory drugs, antiangiogenic thalidomide, and lenalidomide. Targeting IL- 6 is a promising route because it has been shown to protect myeloma cells from apoptosis induced by steroids and chemotherapeutics by PI3/AKT signaling [27]. The IL-6 neutralizing monoclo- nal antibody siltuximab has become available recently and has antimyeloma activity in combination with bortezomib [28], dexamethasone [29], and melphalan [30] in preclinical myeloma models. Three phase II studies using siltuximab are now in progress, based on the results of these in vitro studies. The positive correlation between IL-6 and PML and the poor prognosis of high PML expression at diagnosis in the 2-year survival in this study suggests the possibility of combination therapy of arsenic trioxide, which is an inhibitor for PML [14] and induces apoptosis in the plasma cells of MM patients [31], and siltuximab may be effective for therapy-resistant MM.

The therapeutic strategies for MM have changed significantly from the classical combination chemotherapy over the last two decades. The findings obtained in this study should therefore positively contribute to the improved management of MM cases with new-generation therapies.

\section{Acknowledgments}

We thank Yoshihiko Nakamura, Hideyuki Matsuzawa, Tomomi Takanashi, Yin Sheng, Yara Yukie Kikuti, Hideki Hayashi, and Masayuki Tanaka for their expert technical assistance. This work was supported by 2009 Tokai University School of Medicine Research Aid and a grant from the MEXT (The Ministry of Education, Culture, Sports, Science, and Technology of Japan)-Supported Program for the Strategic Research Foundation at Private Universities.

\section{References}

1 Palumbo A, Anderson K: Multiple myeloma. N Engl J Med 2010;364:1046-1060.

- Ahsmann EJ, Lokhorst HM, Dekker AW, Bloem AC: Lymphocyte function-associated antigen-1 expression on plasma cells correlates with tumor growth in multiple myeloma. Blood 1992;79:2068-2075.

- 3 Teoh G, Anderson KC: Interaction of tumor and host cells with adhesion and extracellular matrix molecules in the development of multiple myeloma. Hematol Oncol Clin North Am 1997;11:27-42.

-4 Hideshima T, Mitsiades C, Tonon G, Richardson PG, Anderson KC: Understanding multiple myeloma pathogenesis in the bone marrow to identify new therapeutic targets. Nat Rev Cancer 2007;7:585-598.
5 Kawano M, Hirano T, Matsuda T, Taga T, Horii Y, Iwato K, Asaoku H, Tang B, Tanabe $\mathrm{O}$, Tanaka H, Kuramoto A, Kishimoto T: Autocrine generation and requirement of BSF2/IL-6 for human multiple myelomas. Nature 1988;332:83-85.

-6 Anderson KC, Jones RM, Morimoto C, Leavitt P, Barut BA: Response patterns of purified myeloma cells to hematopoietic growth factors. Blood 1989;73:1915-1924.

$\checkmark 7$ Klein B, Zhang XG, Jourdan M, Content J, Houssiau F, Aarden L, Piechaczyk M, Bataille R: Paracrine rather than autocrine regulation of myeloma-cell growth and differentiation by interleukin-6. Blood 1989;73: 517-526.

$\checkmark 8$ Uchiyama H, Barut BA, Mohrbacher AF, Chauhan D, Anderson KC: Adhesion of human myeloma-derived cell lines to bone marrow stromal cells stimulates interleukin-6 secretion. Blood 1993;82:3712-3720.
-9 Zhong S, Salomoni P, Ronchetti S, Guo A, Ruggero D, Pandolfi PP: Promyelocytic leukemia protein (PML) and Daxx participate in a novel nuclear pathway for apoptosis. J Exp Med 2000;191:631-640.

10 Bernardi R, Papa A, Pandolfi PP: Regulation of apoptosis by PML and the PML-NBs. Oncogene 2008;27:6299-6312.

11 Jensen K, Shiels C, Freemont PS: PML protein isoforms and the RBCC/TRIM motif. Oncogene 2001;20:7223-7233.

12 Gurrieri C, Capodieci P, Bernardi R, Scaglioni PP, Nafa K, Rush LJ, Verbel DA, CordonCardo C, Pandolfi PP: Loss of the tumor suppressor PML in human cancers of multiple histologic origins. J Natl Cancer Inst 2004; 96:269-279.

13 Lee HE, Jee CD, Kim MA, Lee HS, Lee YM, Lee BL, Kim WH: Loss of promyelocytic leukemia protein in human gastric cancers. Cancer Lett 2007;247:103-109. 
- 14 Ito K, Bernardi R, Morotti A, Matsuoka S, Saglio G, Ikeda Y, Rosenblatt J, Avigan DE, Teruya-Feldstein J, Pandolfi PP: PML targeting eradicates quiescent leukaemia-initiating cells. Nature 2008;453:1072-1078.

15 Greipp PR, San Miguel J, Durie BG, Crowley JJ, Barlogie B, Blade J, Boccadoro M, Child JA, Avet-Loiseau H, Kyle RA, Lahuerta JJ, Ludwig H, Morgan G, Powles R, Shimizu K, Shustik C, Sonneveld P, Tosi P, Turesson I, Westin J: International staging system for multiple myeloma. J Clin Oncol 2005;23: 3412-3420.

16 Salomoni P: Stemming out of a new PML era? Cell Death Differ 2009;16:1083-1092.

17 Dick JE: Stem cell concepts renew cancer research. Blood 2008;112:4793-4807.

18 Ishikawa F, Yoshida S, Saito Y, Hijikata A, Kitamura H, Tanaka S, Nakamura R, Tanaka T, Tomiyama H, Saito N, Fukata M, Miyamoto T, Lyons B, Ohshima K, Uchida N, Taniguchi S, Ohara O, Akashi K, Harada M, Shultz LD: Chemotherapy-resistant human AML stem cells home to and engraft within the bone-marrow endosteal region. Nat Biotechnol 2007;25:1315-1321.

19 Krejci J, Harnicarova A, Kurova J, Uhlirova R, Kozubek S, Legartova S, Hajek R, Bartova E: Nuclear organization of PML bodies in leukaemic and multiple myeloma cells. Leuk Res 2008;32:1866-1877.

20 Aggarwal R, Ghobrial IM, Roodman GD: Chemokines in multiple myeloma. Exp Hematol 2006;34:1289-1295.
21 Kim SJ, Uehara H, Karashima T, McCarty M, Shih N, Fidler IJ: Expression of interleukin-8 correlates with angiogenesis, tumorigenicity, and metastasis of human prostate cancer cells implanted orthotopically in nude mice. Neoplasia 2001;3:33-42.

22 Koch AE, Polverini PJ, Kunkel SL, Harlow LA, DiPietro LA, Elner VM, Elner SG, Strieter RM: Interleukin- 8 as a macrophagederived mediator of angiogenesis. Science 1992;258:1798-1801.

23 Giuliani N, Bonomini S, Romagnani P, Lazzaretti M, Morandi F, Colla S, Tagliaferri S, Lasagni L, Annunziato F, Crugnola M, Rizzoli V: CXCR3 and its binding chemokines in myeloma cells: expression of isoforms and potential relationships with myeloma cell proliferation and survival. Haematologica 2006;91:1489-1497.

24 Ohbayashi N, Kawakami S, Muromoto R, Togi S, Ikeda O, Kamitani S, Sekine Y, Honjoh T, Matsuda T: The IL-6 family of cytokines modulates STAT3 activation by desumoylation of PML through SENP1 induction. Biochem Biophys Res Commun 2008; 371:823-828.

25 Laredj LN, Ferguson BJ, Rich T: Microbial and acute phase stimuli disrupt promyelocytic leukemia tumor suppressive nodes. Mol Immunol 2008;45:1477-1484.

26 Lunardi A, Gaboli M, Giorgio M, Rivi R, Bygrave A, Antoniou M, Drabek D, Dzierzak E, Fagioli M, Salmena L, Botto M, Cordon-Cardo C, Luzzatto L, Pelicci PG, Grosveld F, Pandolfi PP: A role for PML in innate immunity. Genes Cancer 2011;2:10-19.
7 Frassanito MA, Cusmai A, Iodice G, Dammacco F: Autocrine interleukin-6 production and highly malignant multiple myeloma: relation with resistance to drug-induced apoptosis. Blood 2001;97:483-489.

28 Voorhees PM, Chen Q, Kuhn DJ, Small GW, Hunsucker SA, Strader JS, Corringham RE, Zaki MH, Nemeth JA, Orlowski RZ: Inhibition of interleukin- 6 signaling with CNTO 328 enhances the activity of bortezomib in preclinical models of multiple myeloma. Clin Cancer Res 2007;13:6469-6478.

29 Voorhees PM, Chen Q, Small GW, Kuhn DJ, Hunsucker SA, Nemeth JA, Orlowski RZ: Targeted inhibition of interleukin- 6 with CNTO 328 sensitizes pre-clinical models of multiple myeloma to dexamethasone-mediated cell death. Br J Haematol 2009;145:481490.

30 Hunsucker SA, Magarotto V, Kuhn DJ, Kornblau SM, Wang M, Weber DM, Thomas SK, Shah JJ, Voorhees PM, Xie H, Cornfeld M, Nemeth JA, Orlowski RZ: Blockade of interleukin-6 signalling with siltuximab enhances melphalan cytotoxicity in preclinical models of multiple myeloma. Br J Haematol 2011;152:579-592.

31 Rousselot P, Labaume S, Marolleau J-P, Larghero J, Noguera MH, Brouet JC, Fermand JP: Arsenic trioxide and melarsoprol induce apoptosis in plasma cell lines and in plasma cells from myeloma patients. Cancer Res 1999;59:1041-1048. 